Capel, S. (2001) Secondary students' development as teachers over the course of a PGCE year. Educational Research, 43 (3), 247-261

\title{
SECONDARY STUDENTS' DEVELOPMENT AS TEACHERS OVER THE COURSE OF A PGCE YEAR
}

\author{
by \\ Susan Capel \\ Brunel University
}

Key words: concerns; development; PGCE course

\begin{abstract}
Research has suggested that students pass through different concerns or stages in their development as teachers. Although some authors have suggested that concerns or stages are sequential, other research does not support sequential concerns or stages of development. The major purpose of this study was to look at the concerns of students at different times during a one year Postgraduate Certificate in Education (PGCE) course, particularly to identify any changes in concerns about school experience as they developed as teachers and whether the development of concerns was sequential. A second purpose was to look at whether the Teacher Concerns Questionnaire (TCQ) is a useful instrument for measuring students' concerns. One cohort of students on a secondary PGCE course in England was administered the TCQ on three occasions during the academic year 1996/97. Results showed that these students were moderately concerned about school experience at the three administrations of the questionnaire. Self and impact concerns were the highest causes of concern and task concerns the lowest causes of concern at all three administrations of the questionnaire. Results also showed that there was a significant difference in the amount of total concern between the first and second and first and third administrations of the questionnaire, but not between the second and third administrations. There were significant differences between scores on nine of the items on the TCQ. However, there were no significant differences between students learning to teach different subjects. The three categories of concern identified for the TCQ: self; task; and impact concerns were only partly supported by the results of this study. The results did not support work which has suggested that the development of concerns is sequential. The results are discussed in relation to the ongoing development of teachers and identifying concerns of individual students.
\end{abstract}

\section{Introduction}

Research has suggested that students pass through different stages in their development as teachers (e.g. Berliner, 1988; Fuller, 1969; Maynard and Furlong, 1993). Much of the work on students' stages of development has stemmed from the work of Fuller (1969) who identified different concerns of students at different stages during their development as teachers. Concerns were defined as 
perceived problems or worries. Fuller suggested that in a new situation requiring interaction with other people, people are initially most concerned about themselves and the demands made on them by the situation. Only when these initial concerns about self have been addressed do they become concerned about the task of teaching and then about meeting the needs of individual pupils (impact concerns). Fuller and Bown (1975) refined Fuller’s (1969) concerns theory by identifying three stages of concern through which teachers pass in their development: self concerns (coping and survival in the teaching environment, e.g. being able to control the class, being liked by the pupils, finding a place in the power structure of the school, understanding expectations of supervisors, principals and parents and being observed and evaluated); task concerns (mastering the routines and day-to-day tasks of teaching, including working with too many pupils, lack of instructional materials and time pressures); and impact concerns (concerns for, and about, the learning of pupils, pupils' progress and ways in which the teacher can enhance this progress, e.g. recognising the social and emotional needs of pupils, being fair to all pupils, recognising the effect of teaching on individual pupils and being able to individualise teaching and tailor content to maximise intellectual and emotional growth based on pupils' learning problems, motivation).

Other authors have identified stages of development in learning to teach. For example, Maynard and Furlong (1993) identified five stages in the development of students:

- early idealism which occurs before school experience has started. At this stage students are often idealistic in their feelings towards their pupils, identifying with the perspectives of pupils rather than those of the class teacher;

- survival which occurs as students start their school experience. At this stage the realities of the classroom replace the earlier idealism. The major focus becomes class control, classroom management, fitting into the school and becoming established as a teacher;

- recognising difficulties which occurs as students, having survived the initial adjustment to the realities of teaching, become sensitive to the different demands placed on them. They often think about being assessed on their teaching, wondering whether they will be good enough and therefore wanting to perform well. This often results in them focusing on teaching methods and materials;

- hitting the plateau which occurs after students have learned how to control their classes and have identified what does and does not work in the classroom. They therefore want to 'stick to' what works. At this stage they often have trouble changing the focus from themselves and the material they are teaching to focus on the needs of the pupils; and

- moving on which occurs when students can make this shift and therefore can focus on the needs of pupils and experiment with their teaching. 
Both Fuller and Bown (1975) and Maynard and Furlong (1993) suggested that development is sequential, i.e. that students pass through one concern or stage of development before they are ready for the next concern or stage of development. Some studies have identified changes in students' concerns which support the notion of developmental stages, e.g. Pigge and Marso (1987a); Reeves and Kazelskis (1985); Richards and Gipe (1987). On the other hand, some studies have not identified changes in concerns associated with stages of development, e.g. Calderhead (1987); Capel (1998a); Guillaume and Rudney (1993); Pigge and Marso (1987b).

For example, Guillaume and Rudney (1993) identified a wide range of concerns which they grouped into six broad categories: lesson planning and evaluation; discipline; working with pupils; working with co-operating teachers and adjusting to their classrooms; working with others in the profession; and transitions from student to professional teacher. These six categories of concern were present in all three terms of the teacher education programme being followed by the students in the study. At the same time as being concerned about surviving in the classroom, students' expressed concern about their teaching and their pupils. However, the nature of the concerns and the emphasis within each category was found to shift as students developed towards independence, changing from the role of student to taking on the role of the teacher, e.g. students' views of lesson planning and of evaluation changed from a narrow to a broader focus, suggesting an expansion in thinking; students' concerns about discipline changed from focusing on using specific techniques to building a relationship with their pupils based on legitimate authority. Thus, Guillaume and Rudney (ibid) suggested that although students develop over the course of their initial teacher education course, their concerns are not sequential.

\section{Purpose of the study}

Although some authors have suggested that there are sequential concerns or stages which students pass through in their development as teachers, other research does not support sequential concerns or stages of development.

Many different instruments have been used to measure students' concerns. One instrument which has been used in a number of studies is the Teacher Concerns Questionnaire (TCQ) George, 1978) which was developed from Fuller’s work on concerns (Fuller, 1969; Fuller and Bown, 1975).

The major purpose of this study was to look at the concerns of students at different times during a one year Postgraduate Certificate in Education (PGCE) course, particularly to identify any changes in concerns about school experience as students developed as teachers and whether the development 
of concerns was sequential. The second purpose was to look at whether the TCQ is a useful instrument for measuring students' concerns.

\section{Methods}

\section{Subjects and procedures:}

During the academic year 1996-97, one cohort of students on a one year secondary PGCE course were administered a questionnaire on three occasions: (i) at the beginning of the year in September 1996, after they had completed the first week of the course but before they had undertaken any school experience; (ii) in January 1997, at the beginning of the second term of the course, after they had completed a seven week serial experience of two days per week in school and three days per week in the higher education institution and a four week block of school experience in one school; and (iii) in July 1997, towards the end of the year after they had completed all school experiences. Responses were received from: 205 students at the first administration of the questionnaire; 181 students at the second administration of the questionnaire; and 217 students at the third administration of the questionnaire. A total of 240 students (110 (46\%) male and 130 (54\%) female) returned the questionnaire at one or more administrations of the questionnaire. These students comprised the sample for this study. These students were learning to teach the following subjects:

\begin{tabular}{|l|l|l|l|l|l|}
\hline Subject & $\begin{array}{l}\text { Number of } \\
\text { students }\end{array}$ & Percent & Subject & $\begin{array}{l}\text { Number of } \\
\text { students }\end{array}$ & Percent \\
\hline & & & & & \\
\hline art and design & 18 & 7.5 & music & 17 & 7.1 \\
\hline English & 29 & 12.1 & physical education & 25 & 10.4 \\
\hline History & 23 & 9.6 & religious studies & 12 & 5.0 \\
\hline Mathematics & 19 & 7.9 & science & 46 & 19.2 \\
\hline $\begin{array}{l}\text { modern foreign } \\
\text { languages }\end{array}$ & 34 & 14.2 & subject not known & 17 & 7.1 \\
\hline
\end{tabular}

The age range of the students varied from 21 years to 55 years, with a mean age of 28.5 years. Students had varied backgrounds; some coming directly from their undergraduate degree course; some coming from industry because they wanted a change of career; some wanting to start a career, including a number of students who were returning to work after bringing up a family. The qualifications and experience of these students were therefore very broad, but each related to the subject which individual students were learning to teach.

\section{The course:}

The 36 week PGCE course being followed by these students is for the 11-18 age range. Twenty four weeks of the course are spent in school and 12 weeks in the higher education institution. After a three week induction period in the higher education institution, students spend two days per week in 
school and three days in the higher education institution, for seven weeks. This serial experience is followed by a block experience of four weeks. In the first half of the second term (6 weeks), four days per week are spent in a different type of school, with one day per week in the higher education institution. This is followed by a twelve week school experience, spanning the second and third terms. The final three weeks of the course are spent in the higher education institution preparing students for work as a newly qualified teacher.

The course is organised in partnership with approximately 75 schools. There are many different types of schools in the partnership. They include high schools, comprehensive schools, technology schools, secondary modern schools, grammar schools and independent schools. Schools are grouped into 13 geographic consortia. During the year students are placed in two schools in one of the 13 consortia. To support students in school, there are specially trained school subject and professional mentors, as well as higher education institution subject and professional tutors.

\section{Instruments:}

In order to measure changes in concern over time, the TCQ (George, 1978) was administered on three occasions during the course: in September 1996 (before any school experience had been undertaken); in January 1997 (after the first serial and block school experiences had been completed); and in July 1997 (at the end of the PGCE year, after all school experiences had been completed).

The TCQ is based on Fuller's concerns theory (Fuller, 1969). It contains 15 items which measure self, task and impact concerns (see Table 1). Specifically, items 3, 7, 9, 13 and 15 measure self concerns; items 1, 2, 5, 10 and 14 measure task concerns; and items 4, 6, 8, 11 and 12 measure impact concerns.

Table 1: The items on the Teacher Concerns Questionnaire (TCQ) (George, 1978) (items grouped by concerns)

\begin{tabular}{|l|l|} 
& Self concerns \\
\hline $\mathbf{3}$ & Doing well when a supervisor is present \\
\hline $\mathbf{7}$ & Feeling more adequate as a teacher \\
\hline $\mathbf{9}$ & Being accepted and respected by professional persons \\
\hline $\mathbf{1 3}$ & Getting a favourable evaluation of my teaching \\
\hline $\mathbf{1 5}$ & Maintaining the appropriate degree of class control \\
\hline & \\
\hline & Task concerns \\
\hline $\mathbf{1}$ & Lack of instructional materials \\
\hline $\mathbf{2}$ & Feeling under pressure much of the time \\
\hline $\mathbf{5}$ & Too many instructional duties \\
\hline $\mathbf{1 0}$ & Working with too many students each day \\
\hline
\end{tabular}




\begin{tabular}{|l|l|}
\hline $\mathbf{1 4}$ & The routine and inflexibility of the teaching situation \\
\hline & \\
\hline & Impact concerns \\
\hline $\mathbf{4}$ & Meeting the needs of different kinds of students \\
\hline $\mathbf{6}$ & Diagnosing student learning problems \\
\hline $\mathbf{8}$ & Challenging unmotivated students \\
\hline $\mathbf{1 1}$ & Guiding students toward intellectual and emotional growth \\
\hline $\mathbf{1 2}$ & Whether each student is getting what he/she needs \\
\hline
\end{tabular}

Each item is scored on a five point likert scale, with a score of one meaning not concerned and a score of five meaning extremely concerned. George (1978) reported alpha coefficients ranging from 0.77 to 0.83 on the self and impact concerns scales and 0.67 to 0.71 on the task concerns scale.

\section{Statistical analysis:}

Mean scores and standard deviations were calculated for the TCQ as a whole and for each individual item on the questionnaire. Each item on the TCQ was placed in rank order for each administration of the questionnaire. Repeated measures analysis of variance was conducted to determine whether there was any significant difference between the total concern score and individual items on the TCQ at the three administrations of the questionnaire. It was also conducted to see if there was any significant difference between scores for students following the eight different subjects at the three administrations of the questionnaire. Factor analysis is used to determine 'whether relationships among a number of variables can be reduced to smaller combinations of factors or common components' (Thomas and Nelson, 1985, page 214). Factor analysis was conducted on the TCQ at the three administrations, to confirm or otherwise the factor structure of the TCQ.

\section{Results}

\section{Descriptive results:}

As Table 2 shows, the mean score for total concern on the TCQ was 3.12, 2.83 and 2.80 at the first, second and third administrations of the questionnaire, respectively.

At the first administration of the questionnaire these students found the item causing most concern was 'maintaining the appropriate degree of class control' (mean = 3.71) (ranked seventh and ninth at the second and third administrations of the questionnaire, respectively). At the second and third administrations of the questionnaire these students found the item causing most concern was 'meeting the needs of different kinds of students' (mean $=3.43$ and 3.28, respectively) (ranked sixth at the first administration of the questionnaire). 
Items which ranked in the top six at all three administrations of the questionnaire were 'meeting the needs of different kinds of students', 'challenging unmotivated students', 'whether each student is getting what he/she needs', 'getting a favourable evaluation of my teaching' and 'doing well when a supervisor is present'. Of the items ranked in the top six, three items were self concerns and three were impact concerns at the first administration of the questionnaire; and four items were impact concerns and two were self concerns at the second and third administrations of the questionnaire.

Table 2: Means and standard deviations for the total concern score and individual items on the TCQ (in rank order)

\begin{tabular}{|c|c|c|c|c|c|c|c|c|c|c|c|}
\hline \multicolumn{4}{|c|}{$\begin{array}{l}\text { First administration of the } \\
\text { questionnaire }\end{array}$} & \multicolumn{4}{|c|}{$\begin{array}{c}\text { Second administration of the } \\
\text { questionnaire }\end{array}$} & \multicolumn{4}{|c|}{$\begin{array}{c}\text { Third administration of the } \\
\text { questionnaire }\end{array}$} \\
\hline Rank & $\begin{array}{l}\text { Item } \\
\text { No. }\end{array}$ & Mean & SD & Rank & $\begin{array}{l}\text { Item } \\
\text { No. }\end{array}$ & Mean & SD & Rank & $\begin{array}{l}\text { Item } \\
\text { No. }\end{array}$ & Mean & SD \\
\hline & $\begin{array}{l}\text { Total } \\
\text { concern } \\
\text { score }\end{array}$ & 3.12 & 1.04 & & $\begin{array}{l}\text { Total } \\
\text { concern } \\
\text { score }\end{array}$ & 2.83 & 1.02 & & $\begin{array}{l}\text { Total } \\
\text { concern } \\
\text { score }\end{array}$ & 2.80 & 0.65 \\
\hline 1 & 15 & 371 & 111 & 1 & 4 & 3.43 & 098 & 1 & 4 & 328 & 101 \\
\hline $2=$ & 8 & 3.58 & 1.02 & 2 & 8 & 3.34 & 1.04 & 2 & 12 & 3.19 & 0.99 \\
\hline $2=$ & 13 & 3.58 & 1.02 & 3 & 12 & 3.26 & 0.93 & 3 & 8 & 3.20 & 1.05 \\
\hline 4 & 12 & 3.48 & 0.92 & 4 & 13 & 3.22 & 1.08 & 4 & 6 & 3.11 & 0.97 \\
\hline 5 & 3 & 3.47 & 1.04 & 5 & 6 & 3.16 & 0.95 & 5 & 3 & 3.05 & 1.15 \\
\hline 6 & 4 & 3.42 & 1.02 & 6 & 3 & 3.14 & 1.05 & 6 & 13 & 3.04 & 1.10 \\
\hline 7 & 6 & 3.29 & 1.00 & 7 & 15 & 3.12 & 1.19 & 7 & 11 & 2.90 & 1.11 \\
\hline 8 & 7 & 3.22 & 1.06 & 8 & 7 & 2.84 & 1.02 & 8 & 2 & 2.80 & 1.01 \\
\hline 9 & 2 & 3.06 & 1.04 & 9 & 11 & 2.75 & 0.98 & 9 & 15 & 2.75 & 1.14 \\
\hline 10 & 11 & 2.96 & 1.13 & 10 & 2 & 2.69 & 1.04 & 10 & 9 & 2.58 & 1.10 \\
\hline 11 & 9 & 2.86 & 1.13 & 11 & 9 & 2.57 & 0.98 & 11 & 7 & 2.55 & 1.04 \\
\hline 12 & 5 & 2.74 & 0.89 & 12 & 5 & 2.34 & 0.92 & 12 & 5 & 2.51 & 0.97 \\
\hline 13 & 14 & 2.52 & 1.05 & 13 & 1 & 2.30 & 0.98 & 13 & 1 & 2.49 & 1.01 \\
\hline 14 & 1 & 2.50 & 1.03 & 14 & 14 & 2.28 & 0.91 & 14 & 14 & 2.34 & 1.00 \\
\hline 15 & 10 & 2.47 & 1.05 & 15 & 10 & 2.00 & 1.08 & 15 & 10 & 2.26 & 0.90 \\
\hline
\end{tabular}

The item causing least concern at all three administrations of the questionnaire was 'working with too many students each day' (means $=2.47,2.00$ and 2.26 at the first, second and third administrations of the questionnaire, respectively). At all three administrations of the questionnaire, five of the six items ranked lowest as causes of concern were the same. The other four items were 'lack of instructional materials', 'the routine and inflexibility of the teaching situation', 'too many instructional duties' and 'being accepted and respected by other professional persons'. Four of these five items are task concerns, the other is a self concern.

\section{Analysis of Variance:}

Repeated measures analysis of variance showed that that there were significant differences for total concern and for nine of the 15 items on the TCQ. Four of the individual items were self concerns, 
three were task concerns and two were impact concerns. For total concern and all items except one, the significant differences were between the first and second and/or first and third administrations of the questionnaire. The only item on which there was significant difference between the three administrations of the questionnaire was 'maintaining the appropriate degree of class control'. On this item there was a significant decrease in concern between all three administrations of the questionnaire. The significant differences for total concern and the individual items on the TCQ are shown in Table 3.

Table 3: Repeated measures analysis of variance between total concern score on the TCQ at all three administrations of the questionnaire

\begin{tabular}{|c|c|c|c|c|}
\hline $\begin{array}{l}\text { Item on the } \\
\text { TCQ }\end{array}$ & $\begin{array}{l}\text { Degrees of } \\
\text { Freedom }\end{array}$ & $\mathbf{F}$ & Significance & $\begin{array}{l}\text { Significant differences between } \\
\text { administrations of the TCQ }\end{array}$ \\
\hline Total concern & 164,2 & 13.76 & $\mathrm{p}<.0001$ & between 1 and 2 and 1 and 3 \\
\hline 1 & & & not significant & \\
\hline 2 & 164,2 & 8.8 & $\mathrm{p}<.0001$ & between 1 and 2 \\
\hline 3 & 164,2 & 9.31 & $\mathrm{p}<.0001$ & between 1 and 3 \\
\hline 4 & & & not significant & \\
\hline 5 & 164,2 & 4.99 & $\mathrm{p}=0.008$ & between 1 and 2 \\
\hline 6 & & & not significant & \\
\hline 7 & 164,2 & 13.84 & $\mathrm{p}<.0001$ & between 1 and 3 \\
\hline 8 & 164,2 & 4.05 & $\mathrm{p}=0.02$ & between 1 and 3 \\
\hline 9 & & & not significant & \\
\hline 10 & 164,2 & 5.02 & $\mathrm{p}=0.008$ & between 1 and 2 \\
\hline 11 & & & not significant & \\
\hline 12 & 164, 2 & 5.16 & $\mathrm{p}=0.007$ & between 1 and 3 \\
\hline 13 & 164,2 & 14.48 & $\mathrm{p}<.0001$ & between 1 and 3 \\
\hline 14 & & & not significant & \\
\hline 15 & 164, 2 & 24.17 & $\mathrm{p}<.0001$ & between 1 and 2, 1 and 3 and 2 and 3 \\
\hline
\end{tabular}

Repeated measures analysis of variance showed no significant differences between students learning to teach different subjects.

\section{Factor analysis:}

The TCQ was subject to principal components factor analysis on all three occasions that it was administered. At the first administration of the questionnaire the first extracted factor accounted for $36.7 \%$ of the total variance, with all 15 items loading positively on this factor. Loadings ranged from .410 to .679. At the second administration of the questionnaire the first extracted factor accounted for $35.9 \%$ of the total variance, with all 15 items loading positively on this factor. Loadings ranged from .509 to .829 . At the third administration of the questionnaire the first extracted factor accounted for $38.8 \%$ of the total variance, with all 15 items loading positively on this factor. Loadings ranged from .441 to .802 . The loadings after the three school experiences are shown in Table 4.

Table 4: Loadings of items on the first (unrotated) factor on the TCQ at the three administrations of the questionnaire 


\begin{tabular}{|l|l|l|l|l|l|}
\hline \multicolumn{2}{|l|}{$\begin{array}{l}\text { First administration of the } \\
\text { questionnaire }\end{array}$} & \multicolumn{2}{l|}{$\begin{array}{l}\text { Second administration of the } \\
\text { questionnaire }\end{array}$} & \multicolumn{2}{l|}{$\begin{array}{l}\text { Third administration of the } \\
\text { questionnaire }\end{array}$} \\
\hline Item & $\begin{array}{l}\text { Loading on the first } \\
\text { (unrotated factor) }\end{array}$ & Item & $\begin{array}{l}\text { Loading on the second } \\
\text { (unrotated factor) }\end{array}$ & Item & $\begin{array}{l}\text { Loading on the third } \\
\text { (unrotated factor) }\end{array}$ \\
\hline 12 & .679 & 3 & .829 & 4 & .802 \\
11 & .668 & 5 & .758 & 7 & .764 \\
15 & .636 & 13 & .755 & 5 & .744 \\
8 & .616 & 4 & .738 & 12 & .720 \\
4 & .569 & 12 & .718 & 13 & .694 \\
9 & .566 & 11 & .699 & 6 & .677 \\
6 & .565 & 14 & .658 & 11 & .673 \\
3 & .553 & 7 & .637 & 8 & .644 \\
5 & .514 & 6 & .631 & 15 & .633 \\
7 & .493 & 9 & .568 & 14 & .581 \\
14 & .471 & 15 & .548 & 3 & .560 \\
13 & .443 & 2 & .547 & 2 & .519 \\
1 & .432 & 8 & .539 & 10 & .513 \\
2 & .420 & 10 & .523 & 1 & .493 \\
10 & .410 & 1 & .509 & 9 & .441 \\
\hline
\end{tabular}

Varimax rotation yielded the best rotated factor matrix with an orthogonal solution at all three administrations of the questionnaire. At the first administration of the questionnaire three factors emerged. These three factors had eigen values of 5.51, 1.37 and 1.16 and accounted for $36.7 \%, 9.2 \%$ and $7.7 \%$ of the total variance, respectively. At the second administration of the questionnaire four factors emerged. These four factors had eigen values of 5.38, 1.77, 1.38 and 1.12 and accounted for $35.9 \%, 11.8 \%, 9.2 \%$ and $7.5 \%$ of the total variance, respectively. At the third administration of the questionnaire four factors emerged. These four factors had eigen values of 5.82, 1.37, 1.22 and 1.04 and accounted for $38.8 \%, 9.2 \%, 8.1 \%$ and $7.0 \%$ of the total variance, respectively. Items with loadings greater than .40 are shown in Table 5. Three of the factors identified were the same at the three administrations of the questionnaire. Factor one was labelled 'impact concerns', factor two 'self concerns' and factor three 'task concerns'. At the second and third administrations of the questionnaire a fourth factor was identified. At the second administration of the questionnaire this was labelled 'evaluation concern' and at the third administration of the questionnaire this was labelled 'adequacy concern'.

Table 5: Sources of concern on the TCQ: loadings greater than .40 on varimax rotated factors

\begin{tabular}{|c|c|c|c|c|}
\hline $\begin{array}{l}\text { First administration of the } \\
\text { questionnaire }\end{array}$ & \multicolumn{2}{|c|}{$\begin{array}{l}\text { Second administration of the } \\
\text { questionnaire }\end{array}$} & \multicolumn{2}{|c|}{$\begin{array}{l}\text { Third administration of the } \\
\text { questionnaire }\end{array}$} \\
\hline \multicolumn{5}{|c|}{ FACTOR ONE } \\
\hline item number & item loading & loading & item number & loading \\
\hline impact concern & \multicolumn{2}{|c|}{ impact concern } & \multicolumn{2}{|c|}{ impact concern } \\
\hline 7779 & 12 & .793 & 4 & .810 \\
\hline .738 & 4 & .792 & 12 & .697 \\
\hline .735 & 6 & .756 & 6 & .659 \\
\hline .704 & 11 & .714 & 11 & .623 \\
\hline .558 & 8 & .542 & 8 & .554 \\
\hline
\end{tabular}




\begin{tabular}{|c|c|c|c|c|c|}
\hline 5 & .519 & & & 1 & .510 \\
\hline \multicolumn{6}{|c|}{ FACTOR TWO } \\
\hline \multicolumn{2}{|c|}{ task concern } & \multicolumn{2}{|c|}{ task concern } & \multicolumn{2}{|c|}{ task concern } \\
\hline 2 & .629 & 5 & .793 & 5 & .770 \\
\hline 1 & .623 & 14 & .785 & 14 & .701 \\
\hline 3 & .579 & 2 & .638 & 2 & .590 \\
\hline 14 & .535 & 10 & .528 & 10 & .564 \\
\hline 10 & .481 & & & & \\
\hline \multicolumn{6}{|c|}{ FACTOR THREE } \\
\hline \multicolumn{2}{|c|}{ self concern } & \multicolumn{2}{|c|}{ self concern } & \multicolumn{2}{|c|}{ self concern } \\
\hline 15 & .761 & 7 & .676 & 13 & .777 \\
\hline 9 & .550 & 15 & .655 & 3 & .672 \\
\hline 13 & .542 & 1 & .586 & 9 & .507 \\
\hline 7 & .528 & 9 & .527 & & \\
\hline \multicolumn{6}{|c|}{ FACTOR FOUR } \\
\hline & & \multicolumn{2}{|c|}{ evaluation concern } & \multicolumn{2}{|c|}{ adequacy concern } \\
\hline & & 3 & .872 & & .811 \\
\hline & & 13 & .775 & 15 & .699 \\
\hline
\end{tabular}

\section{Discussion}

The results of this study have to be interpreted cautiously because of a number of potential weaknesses in the study. First, the sample size was relatively small. Linked to this, the students included in this study were all following the same one year secondary PGCE course at one higher education institution in England. These students were therefore following a course with a specific structure and experiences. Thus, the results from this study may be hard to generalise to students on other courses with other structures.

Second, the number of students included in the analysis of questionnaires was 240 . This represents $92.6 \%$ of the 259 students who remained on the course throughout the year. In addition, some students dropped-out of the course. Results from those students who did not complete the questionnaire at any of the three administrations, or who dropped out of the course, may have shown differences in causes and levels of concern.

Results showed that students were moderately concerned about school experience at all three administrations of the questionnaire. Moderate levels of concern have also been found in other studies of students learning to teach e.g. Capel (1998a); Hart (1987); Paese and Zinkgraf (1991); Silvernail and Costello (1983).

\section{Causes of concern}

Results showed that at all three administrations of the questionnaire self and impact concerns were included in the six items ranked highest as causes of concern. Therefore students were concerned about self and the impact of their teaching throughout their school experiences. Thus, these students held more than one different type of concern at once. 
Within this overall finding, results suggested that the nature of these concerns changed over time as students developed as teachers. At the first administration of the questionnaire the item causing most concern was a self concern 'maintaining the appropriate degree of class control'. This finding supports the concerns identified by Fuller and Bown (1975) and the stages of development identified by Maynard and Furlong (1993) as well as research that has found that discipline is a concern for students early in their experiences of learning to teach, e.g. Hart (1987).

At the second and third administrations of the questionnaire the item causing most concern was an impact concern 'meeting the needs of different kinds of students'. This result suggests a change in concerns over time, with impact concerns becoming more important later in students experiences of learning to teach. This change in the nature of concerns over time supports the work of both Fuller and Bown (1975) and Maynard and Furlong (1993).

At all three administrations of the questionnaire self concerns of 'getting a favourable evaluation of my teaching' and 'doing well when a supervisor is present' were ranked in the top six concerns. These findings support results of a study by Capel (1998a) which found that students were most concerned about observation, evaluation and assessment of their teaching after four school experiences on a four year initial teacher education course.

The item causing least concern at all three administrations of the questionnaire was 'working with too many students each day', followed by other concerns about the task of teaching. A self concern identified as low as a cause for concern at the three administrations of the questionnaire was 'being accepted and respected by professional persons'.

There could be several reasons for the finding that the task of teaching did not cause concern for these students. One reason could be that these students were well prepared for the task of teaching and for the role of a teacher. It could also have been due to the nature of the school-based work that these students were undertaking, which was designed to immerse them gradually into the task of teaching rather than to expect them to be comfortable with the task of teaching from their very early experiences in the classroom. Another possible reason is the nature of the working relationship between the student and mentor, with students having effective support in the development of their teaching skills. The reasons for these findings need to be investigated further.

These results suggested that students did not pass through a sequence of concerns, only becoming concerned about the task of teaching and the impact of their teaching when they had addressed self 
concerns. At all three administrations of the questionnaire both self and impact concerns were ranked high as causes of concern whereas task concerns were consistently ranked low as causes of concern. Thus, these results do not support the sequential development of concerns during the course of a one year secondary PGCE course. Rather, they support the work of Guillaume and Rudney (1993) which suggested that (i) students hold several different concerns at once; and (ii) there is a change in nature of concerns over time as students develop as teachers. Guillaume and Rudney (1993) found that students' thinking about any one concern changes over time and that they also become concerned about different aspects of their teaching. For example, the nature of concern about self changed. High self concern about maintaining the appropriate degree of class control prior to school experience was replaced by high self concern about getting a favourable evaluation of teaching later in the school experiences. This suggested a shift from concern about survival in the classroom to concern about doing well in front of others.

\section{Significant differences between scores at the three administrations of the questionnaire}

The amount of total concern reduced significantly between the first and second and first and third administrations of the questionnaire. This is perhaps to be expected. At the first administration of the questionnaire students had not undertaken any school experiences, but were due to start a serial school experience in the following week. They would be expected to be concerned about what school experience would be like, what would be expected of them and whether they would 'survive' school experience. However, at the second administration of the questionnaire students had 'survived' their first school experience and were ready to start their second block of school experience. At the third administration of the questionnaire students had completed all their school experiences on the course and knew whether or not they had achieved the competencies required to gain qualified teacher status. They were therefore confident in their ability to teach.

There were significant differences in concern on nine of the 15 items on the TCQ between the first and second or first and third administrations of the questionnaire. This finding supports the finding for total concern, above. There was only one item on the TCQ on which there was a significant difference between the score at the second and third administration of the questionnaire 'maintaining the appropriate degree of class control'. There was a decrease in concern from a ranking of one to seven to nine over the three administrations of the questionnaire. This supports the suggestion of a decrease in concern about surviving in the classroom as students learn to teach (e.g. Maynard and Furlong, 1993).

These results could suggest that concern decreases once students gain experience of teaching, but that once students become established in schools, the amount of concern does not continue to 
decrease, there being a baseline concern throughout their course. This suggestion needs to be investigated further.

\section{Factor analysis}

Results of factor analysis revealed three factors at the first administration of the questionnaire and four factors at each of the second and third administrations of the questionnaire. Thus, the factors were not entirely consistent with the three categories of concern identified by George (1978). Only at the second administration of the questionnaire did any of the factors match exactly the concerns identified on each concern scale by George. This factor was impact concerns. However, the three factors identified at the first administration of the questionnaire were roughly the same as the three categories of concern. At the second administration of the questionnaire task concerns roughly matched the items identified by George for the TCQ, but self concerns separated into two factors: self concerns; and evaluation concerns. At the third administration of the questionnaire, impact and task concerns roughly matched those identified by George, but again self concerns separated into two factors: self concerns; and adequacy concerns.

These findings show that, in this study, the task and impact concerns scales seemed generally to be internally consistent and relatively stable over the three administrations of the questionnaire. Therefore, these scales were generally, but not fully, supported. On the other hand, there seemed to be low internal consistency for the self concerns scale, which seemed to be much less stable. Other studies have indicated low internal consistency and instability for the self concerns scale (e.g. Behets, 1990; Boggess, McBride and Griffey, 1985). Thus, the TCQ is not fully supported as an instrument for measuring students’ concerns.

The finding of a fourth factor at the second and third administrations of the questionnaire is interesting. The reason for these additional factors needs to be investigated further, but there may be several possible reasons. At the second administration of the questionnaire the fourth factor identified was evaluation concern. One possible reason for this is the time at which the questionnaire was administered. At this point in their course, these students had completed a seven week serial and a four week block of school experience. They were therefore beginning to teach lessons on their own rather than observing teachers teach or team teaching. They were also being observed on their performance as teachers in order to evaluate the development of their competence as teachers. They were therefore likely to be becoming concerned about how their development was being seen. The concern about being observed and evaluated might be exacerbated in a school-based model of initial teacher education in which subject mentors both facilitate students' learning and assess them on their performance as teachers. Pateman (1994) highlighted the potential stressful effects for students if 
they feel unable to talk freely and openly to their mentor about concerns related to their development as teachers or to their teaching performance due to the mentor's role in assessing their teaching performance.

At the third administration of the questionnaire, the fourth factor identified was adequacy concern. One possible reason for identification of adequacy as a separate factor could be that these students had completed school experience on their course and were anticipating starting teaching as newly qualified teachers. They were therefore anticipating a new situation and may have been concerned that they would not cope adequately in their first teaching post. For example, maintaining discipline/classroom behaviour for a year could have seemed more daunting than maintaining discipline which has previously been established by the class teacher for a short period on school experience. Also, in their first teaching post they were likely to receive less day-to-day support than they did as a student, which may have exacerbated the concern. Adequacy was identified as a concern in two studies by Capel (1998b; 1998c) of the concerns of students at the end of their initial teacher education course.

Students' development as teachers is not complete at the end of their initial teacher education year. Some concerns may not be addressed until the first year of teaching or beyond as teachers continue to develop throughout their career. Further, as the results above suggested, students do not leave concerns behind once and for all; they come back to concerns at different times in their development as circumstances change. Berliner (1988) developed a five stage model of teacher development, focusing on cognitions that underlie teacher's classroom behaviours:

Stage 1: Novice. At this stage teachers are labelling and learning the different elements that make up classroom tasks. Performance in the classroom is rational, relatively inflexible and requires purposeful concentration. Students on school experience and into their first year of teaching are likely to be at this stage.

Stage 2: Advanced beginner. Episodic knowledge is acquired and similarities across contexts are recognised. Teachers develop an understanding of when to ignore and when to break rules as prior classroom experiences and the contexts in which problems are set begin to guide behaviour. Teachers are developing strategic knowledge. Berliner suggested that many second or third year teachers reach this stage. 
Stage 3: Competent. Teachers are able to make conscious choices about actions taken, are able to set priorities and make plans. Teachers use past experiences to understand what is important and what is unimportant. Performance is not yet fluid or flexible.

Stage 4: Proficient. The performance of teachers begins to be guided by intuition and know-how and they acquire a holistic recognition of similarities among contexts. Berliner indicates that teachers in their fifth year of teaching may reach this stage.

Stage 5: Expert. This stage is characterised by an intuitive grasp of situations and non-analytic, nondeliberate sense of appropriate behaviour. Teaching performance is fluid and seemingly effortless as teachers no longer choose the focus of their attention, but operate on automatic pilot and have in place standardised, automated routines to handle instructions and management. Expert teachers are likely to have difficulty in unpacking or describing their cognitions. Berliner suggests that not all teachers reach this stage.

The initial teacher education year is only the beginning of development. Further research is needed into development after the initial teacher education year, into the first year of teaching and beyond. This research could look at whether the model identified by Berliner applies to newly qualified teachers who have followed a one year secondary PGCE course in England.

\section{Conclusion}

Results of this study have suggested that higher amounts of concern are caused by self and impact than by the task of teaching, although within each category of concerns there are changes in the nature of concerns over time. They have also suggested that stages of development of concern are not sequential. Results do not fully support the use of the TCQ as an instrument to measure students' concerns.

Results of this study identify the general concerns of this group of students. They hide differences between individual students. It is important that the concerns of individual students are identified because the concerns of individual students are unique to each student. They may not be those identified for a group of students at any particular time. Students starting an initial teacher education course have different levels of knowledge, understanding and experience about teaching, schools and pupils which may result in different causes of concern for students (McIntyre, Hagger and Burn, 1994). Further, the interaction between an individual student and school experience situation make a unique set of circumstances for each student. It is important to identify concerns unique to each 
individual student and to help that student address those individual concerns in order to help them develop as teachers. It is important also that students are able to identify their own concerns at any one time, which may enable them to start to address them.

Questionnaires could be useful tools in helping to identify concerns of students in general. The concerns identified may be useful as the basis for developing the structure and order of content of courses. However, questionnaires, including the TCQ, have limited use in identifying the concerns of individual students. Other methods are needed to identify concerns of individual students and then take action to address those concerns. This requires the use of research methods other than questionnaires, e.g. case studies.

\section{References}

Behets, D. (1990). Concerns of preservice physical education teachers. Journal of Teaching in Physical Education, 10 (1), 66-75.

Berliner, D.C. (1988). Implications of studies on expertise in pedagogy for teacher education and evaluation. In: New directions for teacher assessment (Proceedings of the 1988 ETS Invitational Conference). Princeton NJ: Educational Testing Service, pp. 39-68.

Boggess, T.E., McBride, R.E. and Griffey, D.C. (1985). The concerns of physical education student teachers: a developmental view. Journal of Teaching in Physical Education, 4 (3), 202-211.

Calderhead, J. (1987). The quality of reflection in student teachers' professional learning. European Journal of Teacher Education, 19(3), 269-278.

Capel, S. (1998a). A longitudinal study of the stages of development or concern of secondary PE students. European Journal of Physical Education, 3 (2), 185-199.

Capel, S. (1998b). The transition from student teacher to newly qualified teacher: some findings. Journal of In-service Education, 24 (3), 393-409.

Capel, S. (1998c). Experiences of physical education students in learning to teach. European Physical Education Review, 4 (2), 127-144.

Fuller, F.F. (1969). Concerns of teachers: a developmental conceptualization, American Educational Research Journal, 6 (2), 207-226.

Fuller, F.F. and Bown, O.H. (1975). Becoming a Teacher, in K.J. Rehage (Ed.) Teacher Education, NSSE 74th Yearbook, part II, Chicago: University of Chicago Press.

George, A.A. (1978). Measuring self, task, and impact concerns: A manual for use of the teacher concerns questionnaire, Austin, TX: University of Texas, Research and Development Center for Teacher Education.

Guillaume, A.M. and Rudney, G.L. (1993). Student teachers' growth toward independence: an analysis of their changing concerns. Teaching and Teacher Education, 9 (1), 65-80.

Hart, N.I. (1987). Student teachers' anxieties: four measured factors and their relationships to pupil disruption in class, Educational Research, 29 (1), 12-18.

McIntyre, D., Hagger, H. and Burn, K. (1994). The management of student teacher's learning. London: Kogan Page.

Maynard, T. and Furlong, J. (1993). Learning to teach and models of mentoring, in D. McIntyre, H. Hagger and M. Wilkin (Eds.) Mentoring: Perspectives on school-based teacher education, London: Kogan Page, 69-85.

Paese, P.C. and Zinkgraf, S. (1991). The effect of student teaching on teacher efficacy and teacher stress. Journal of Teaching in Physical Education, 10 (3), 307-315.

Pateman, T. (1994). Crisis, what identity crisis? First appointments supplement, Times Educational Supplement, 14 January, 28-29.

Pigge, F.L. and Marso, R.N. (1987a). The influence of preservice training and teaching experience upon attitudes and concerns about teaching. Paper presented at the annual meeting of the 
American Educational Research Association, Washington DC., April.

Pigge, F.L and Marso, R.N. (1987b). Relationships between students characteristics and changes in attitudes, concerns, anxieties and confidence about teaching. Journal of Educational Research, 81, 1009-115.

Reeves, C.K., and Kazelskis, R. (1985). Concerns of preservice and inservice teachers. Journal of Educational Research, 78, 267-271.

Richards, J. and Gipe, J. (1987). Reflective concerns of prospective teachers in an early field placement. Paper presented at the annual meeting of the American Educational Research Association, Washington, DC., April.

Silvernail, D.L. and Costello, M.H. (1983). The impact of student teaching and internship programs on preservice teachers' pupil control perspectives, anxiety levels, and teaching concerns. Journal of Teacher Education, 34, 32-36.

Thomas, J.R. and Nelson, J.K. (1985). Introduction to research in health, physical education, recreation and dance. Champaign, IL.: Human Kinetics. 